\title{
A Framework for Identifying Web-Based Electronic Commerce Opportunities
}

\author{
Frederick J. Riggins \\ DuPree College of Management \\ Georgia Institute of Technology
}

\begin{abstract}
Companies are finding that the development of World Wide Web presence sites is becoming a competitive necessity, particularly the need to establish online storefronts. Even so, there are few useful frameworks in the electronic commerce (EC) literature to help managers identify online opportunities and what types of applications can add business value to the user. I expand on an existing framework originally developed by Hammer and Mangurian [1] to identify opportunities from Web-based EC applications. I argue that firms compete along 5 dimensions of commerce: By using various modes of interaction, firms compete over both time and distance to provide some product or service to their customers through a chain of relations. In addition, new investments in information technology are typically justified using 3 different criteria-generating efficiency, effectiveness, and/or strategic benefits. These 2 perspectives can be combined to create the Electronic Commerce Value Grid, which identifies 15 areas in which managers can use Web-based electronic storefronts to add value for their customers.
\end{abstract}

electronic commerce, Web-based business, business value

\section{INTRODUCTION}

The dollar value of electronic commerce (EC) transactions continues to increase at an astounding rate. In consumer-to-business applications, the amount of money spent by online shoppers is nearly doubling every year and is expected to approach $\$ 5$ billion in 1998 and to top $\$ 12$ billion by the year 2000 [2]. In addition, several estimates predict that by the year 2001, sales via business-to-business EC applications will dwarf consumer-to-business applications [3]. These opportunities are being powered by Web-based, user-friendly online storefronts, which are rapidly becoming a competitive necessity in a variety of industries.

Although the popular press touts such online success stories as Amazon.com [4] and The Motley Fool [5], there are few useful frameworks in the EC literature to help managers identify online opportunities and what types of applications truly

Correspondence and requests for reprints should be sent to Frederick J. Riggins, 755 Ferst Drive, DuPree College of Management, Georgia Institute of Technology, Atlanta, GA 30332-0520. E-mail: fred.riggins@mgt.gatech.edu 
add business value for the firm's trading partners. In this article, I expand on an existing framework originally developed by Hammer and Mangurian [1] to identify opportunities from Web-based EC applications. The resulting EC Value Grid identifies 15 areas where managers can use Web-based electronic storefronts to add value to their customers to create a unique online buying experience.

The EC Value Grid can also be used by researchers who seek to measure the value and impact of Web-based applications on the company's bottom line. By developing a useful classification of Web-based applications, researchers can be sure to compare similar initiatives to determine what environmental, organizational, and technical aspects of an application's implementation results in success or failure. Also, we can develop a measure of Web strategic sophistication for an organization by analyzing its Web site in light of the different types of applications discussed in the framework.

\section{FIVE DIMENSIONS OF COMMERCE}

Firms compete along five dimensions of commerce. By using various modes of interaction, firms compete over both time and distance to provide some product or service through a chain of relations, which eventually ends with the end customer. Hammer and Mangurian [1] focused on the use of communications technology to impact time, geography, and relations. I expand on this to include the impact on altering the nature of the interaction, the potential to offer entirely new products and services, and the application of the framework to Web-based EC. Although many forms of communications media and information technology have the potential to impact these dimensions, the use of Web-based online storefronts provides firms with new ways of altering the importance of each dimension. This is because these applications, when delivered over the Internet, make use of real-time communications, are relatively cost effective to implement and use, are based on the now ubiquitous, user-friendly Web browser, and make use of a variety of information-rich multimedia tools.

In today's competitive business climate, companies now compete on what has become known as Internet time. The time it takes to develop and deliver products is now being measured in days or weeks rather than months or years. Because of this, companies are seeking ways to use the Internet to dramatically reduce or even eliminate the time it takes to deliver information, products, and services on demand. To do this, companies are implementing Internet technology to enable intranets to service users inside the organization and extranets to allow access to those outside the organization.

In addition, geographical distance is virtually meaningless in cyberspace. A coffee and tea seller in Baltimore (http://www.baltcoffee.com) can have immediate access to a global market by setting up an online storefront. However, if you build it, they will not necessarily come. Although physical location takes on little or no meaning, location in cyberspace means having your company logo and hyperlink prominently displayed on any one of several critical Web traffic control sites. Developing strategic alliances with these traffic control sites is becoming critical for generating first-time visits, as the number of Web pages doubles every year. Alli- 
ances with these Web traffic control sites will allow your organization's Web link to be prominently displayed within improved bookmark facilities and a potential customer's personalized link page.

The Internet presents opportunities to alter the structure of relations in both consumer-to-business and business-to-business commerce. In many industries, the Web represents an opportunity for new Internet start-up companies to challenge established firms because the cost of establishing a Web presence can be relatively modest. For example, Security First Network Bank (SFNB) was the first all-Internet bank, which operated for several months without any physical branch office. By offering superior functionality, SFNB was able to get a jump on established banks that possessed superior brand recognition. The trade-off between the brand recognition of established companies and superior functionality often demonstrated by Internet start-up companies is an important area that has not been well researched [6]. On the one hand, in industries that require the development of long-term customer relationships (such as banking), new Internet start-up companies may find it difficult to gain customer loyalty. On the other hand, consumers in many retail markets (such as the sale of books and computer equipment) will exhibit less loyalty, allowing Internet start-ups more opportunity. The phrase "Don't get Amazoned," in reference to the successful online bookseller Amazon.com (http:/ / www.amazon.com), has become synonymous with the warning that a new Internet start-up company can quickly undercut unprepared established companies [2].

The early success of many of these Internet start-ups can be attributed to their superior understanding of how the Internet can be used to alter the interaction between a company and its customers. Because of their lack of brand recognition, new Internet start-ups have sought ways to use the technology to increase customer loyalty, which can be fleeting in cyberspace. Indeed, one of the most powerful uses of the Web has been the creation of online virtual communities of interaction [7, 8]. Rather than replicating traditional forms of interaction, successful Web businesses find new types of interaction to take advantage of the power of the Web medium.

Finally, the powerful multimedia aspects of the Web create opportunities to generate entirely new products and services that were not feasible just a few years ago. These new information products and services can result in new sources of revenue for Web-based businesses or alter the balance of power in existing relations. Although the development of these new types of products can be much more costly than simply developing a simple Web presence, the potential rewards can be impressive.

\section{USING EC TO CREATE NEW VALUE}

New investments in information technology are typically justified by using three different criteria: generating efficiency, effectiveness, and/or strategic benefits. Improving efficiency has traditionally been the primary use of information technology. Even before the Internet, companies were engaged in EC, using electronic data interchange (EDI) to improve the efficiency of coordinating with external trading partners. Today, Internet EDI, online bill presentment and payment, and online shopping arejust a few examples of how the Internet can be used to improve efficiency. 
The opportunity to improve the effectiveness of decision makers by making the right information available on demand is certainly one of the Web's strongest features. These decision makers could be consumers considering a purchasing decision or a manager seeking information to formulate a marketing strategy. Getting the right information to the right person, in the right format, at the right time requires sophisticated Web search and navigation aids, the ability to present content in multiple formats on the fly, and providing access to powerful decision support systems and expert systems.

Finally, the Web can be used for strategic purposes if it results in increased revenues by opening up new markets, new products and services, or by allowing firms to gain advantage over competitors by developing new customer loyalty. As with other strategic uses of information technology, being the first to market with these Web-based applications can result in at least a temporary competitive advantage. However, long-term advantage can only be obtained by constantly updating the content and functionality of the Web site and by redesigning business processes to take advantage of the new technology.

\section{EC VALUE GRID}

By combining the five dimensions of commerce and the three types of value generated by these applications, we can identify 15 different ways that Web-based applications can be used to generate new business value. These 15 types of Web-based applications are shown in the EC Value Grid (Table 1). Clearly, most Web sites generate value for the user in several ways. Indeed, the EC Value Grid is a tool to measure the strategic sophistication of an organization's Web site. Today, many commercial Web sites provide online storefronts and company information sites (Table 1 , top-left). Truly innovative uses of the technology involve the cultivation of vast virtual communities and the use of online decision support systems (Table 1, bottom-right). The extent to which a particular corporate Web site encompasses several of the cells in the grid is a measure of the strategic sophistication or EC coverage of the site and the organization's commitment to using the site for strategic gain.

\subsection{Operating on Internet Time}

4.1.1 Applications to Accelerate User Tasks. Kalakota and Whinston [9] described several tasks that customers engage in when shopping. These include prepurchase interaction (search for products, comparison of product characteristics, and negotiation of transaction details), purchase interaction (placement of the order, authorization of payment, and product delivery), and postpurchase interaction (customer service and support). All three of these categories can be supported by Web-based interfaces by compressing or eliminating the time required to perform these tasks. In particular, Web-based online storefronts generate efficiency benefits to customers by reducing the time required to complete purchase interaction tasks.

Many retail Web sites offer customers the opportunity to browse online catalogs, place items in their virtual shopping carts, receive authorization for payment, and, in cases where the good is an information product, receive delivery of the 
Table 1

The Electronic Commerce Value Grid

\begin{tabular}{|c|c|c|c|}
\hline \multirow[b]{2}{*}{$\begin{array}{l}\text { Five Dimensions of } \\
\text { Commerce }\end{array}$} & \multicolumn{3}{|c|}{ Value Creation } \\
\hline & Efficiency & Effectiveness & Strategic \\
\hline Time & Accelerate user tasks & $\begin{array}{l}\text { Eliminate information } \\
\text { float }\end{array}$ & $\begin{array}{l}\text { Establish } 24 \times 7 \text { customer } \\
\text { service }\end{array}$ \\
\hline Distance & $\begin{array}{l}\text { Improve scale to look } \\
\text { large }\end{array}$ & $\begin{array}{l}\text { Present single gateway } \\
\text { access }\end{array}$ & Achieve global presence \\
\hline Relationships & $\begin{array}{l}\text { Alter role of } \\
\text { intermediaries }\end{array}$ & $\begin{array}{l}\text { Engage in } \\
\text { micromarketing to } \\
\text { look small }\end{array}$ & $\begin{array}{l}\text { Create dependency to } \\
\text { lock-in user }\end{array}$ \\
\hline Interaction & $\begin{array}{l}\text { Make use of extensive } \\
\text { user feedback }\end{array}$ & $\begin{array}{l}\text { User controls detail of } \\
\text { information accessed }\end{array}$ & $\begin{array}{l}\text { Users interact via online } \\
\text { community }\end{array}$ \\
\hline Product & $\begin{array}{l}\text { Automate tasks using } \\
\text { software agents }\end{array}$ & $\begin{array}{l}\text { Provide online decision } \\
\text { support tools }\end{array}$ & $\begin{array}{l}\text { Bundle information, } \\
\text { products, and services }\end{array}$ \\
\hline
\end{tabular}

product itself online. An excellent example of this is Dell Computers (http:// www.dell.com), which currently sells over \$3 million worth of computer equipment per day from its Web site [2]. An easy-to-use interface allows the user to configure a computer system for purchase, to receive an immediate quote for the configuration in question, and to place the order online. One of the most successful online storefronts is bookseller Amazon.com, which provides access to over 2.5 million titles, available at one Web site [2].

In addition to online storefronts, online banks now allow customers to pay bills online, check account status, apply for a loan or credit card by filling out an electronic form, and, in some cases, aggregate their entire financial portfolio in one browser interface. Two major coalitions, Integrion (made up of 17 major banks, IBM, Visa USA, and Check Free) and MSFDC (with Microsoft, First Data Corp., and several other financial institutions) are fighting to be the first to provide online bill presentment and payment. Both of these coalitions believe that the key to EC in general, and to online banking in particular, will be when billers are able to bill their customers as well as receive payments, online.

4.1.2 Applications to Eliminate Information Float. By using Web to support prepurchase interaction, businesses are able to essentially eliminate information float and thereby improve a decision maker's effectiveness by making information available on a continuous basis. This benefit is particularly useful in situations where information changes quickly and decision making requires up-to-the-minute information updates.

In the financial services industry, a mistimed trade resulting from information even minutes old can have disastrous repercussions. Online stock brokers, such as Fidelity (http://www.fidelity.com) or Schwab (http://www.schwab.com), and information brokers, such as The Wall Street Journal Interactive Edition (http:/ / www.wsj.com), can provide real-time updates of stock quotes, mutual funds, and interest rates. These sites typically provide time-lagged information for free and require a fee for real-time updates. 
Federal Express (http:/ /www.fedex.com) has revolutionized the package delivery industry by allowing users to track any package online using an airbill tracking number. The FedEx.com also provides an easy-to-use dropoff locator function and up-to-the-minute delivery rates. This system has put other package delivery competitors on notice that, in this industry, the delivery of information is nearly as important as the delivery of packages.

The opportunity to eliminate information float is also dramatically changing the way we get our news and other types of information. CNN Interactive (http:/ / cnn.com) has successfully transferred its superior brand name from the television cable industry to the online news and information industry. Using push technology, such as PointCast (http: / / www.pointcast.com), users can identify areas of interest and have news and other information delivered directly to their computer in real time. Using this technology, users can be more informed and up-to-date than by viewing the news on their television.

4.1.3 Applications to Establish $24 \times 7$ Customer Service. Although the Web can be used to deliver information on a real-time basis, the power of the technology is that it is available 24 hours a day, 7 days a week $(24 \times 7)$. This provides an opportunity to provide superior customer service, which is becoming imperative in today's business climate.

Online storefronts or banks are open 24 hours a day. In addition, most corporate Web sites include a page of frequently asked questions (FAQ) that provides users with additional information without the need to directly contact a customer service representative. In addition, many sites provide telephone contact points or e-mail links for specific individuals. Finally, customer service can be enhanced by having a link that generates a telephone call from an designated customer service representative.

\subsection{Web Navigation Takes Precedence Over Physical Distance}

4.2.1 Applications to Improve Scale to Look Large. The Web is considered the great equalizer for many small organizations. By establishing a relatively low-cost, but well-designed Web site, a small organization is able to look large to the average user. In particular, the Web allows small organizations to overcome scale disadvantages by linking together sites that are geographically decentralized into one larger virtual location. In some cases, several small organizations can band together into one virtual site to offer competitive advantages against larger competitors.

This opportunity to overcome scale by bringing together decentralized business units is illustrated by Century21 in the real estate industry (http://www. century21.com). The Century21 home page allows the user to search for residential property anywhere in the country, find out about specific communities, gather information about loan and credit needs, read real estate tips, and locate the physical location of a specific Century21 office. Although an individual office may be able to reproduce much of this information on its own, the site exhibits a positive externality effect in that the site becomes more valuable to the user when more offices are linked to the site. 
One example of different organizations coming together to overcome scale is Auto-By-Tel (http://www.autobytel.com). The Auto-By-Tel Web site brings together 2700 accredited dealers into one virtual auto mall. This allows many small dealerships to band together to compete against larger ones.

4.2.2 Applications to Present a Single Gateway Access. One of the most difficult aspects of providing excellent customer service is providing an easy point of contact to allow the customer to reach the right person in the company. By establishing a presence in cyberspace, a company is able to present a single gateway access to the entire company. This improves the user's information-gathering effectiveness by aggregating information into a single virtual location, regardless of where the information is maintained. In many cases, a particular Web site can become a trusted filter directing users to other sites where related information can be found. This can dramatically increase the power of that company in its respective industry.

The General Motors home page (http:/ / www.gm.com) presents a single gateway interface, where the user can find out about GM services around the world, link to the various GM division home pages, find out about financing arrangements, and locate the nearest GM dealer. This type of single gateway interface is becoming a necessity to reach online customers.

Millipore (http:/ / www.millipore.com) is a leader in purification and filtering technology. One of the most interesting aspects of its Web site is the Millipore Biopharmaceutical HyperFilter, which provides Web links to biotechnology and pharmaceutical sites. Using this "filter," the user can link to other companies in the industry, university research sites, governmental and regulatory sites, and related publication sites. By becoming a trusted filter of information in this field, Millipore has established itself as a leader with a focus on customer service. This also boosts traffic to its site- on its way to becoming an information clearinghouse in the industry.

Several general, well-branded Web traffic-control sites generate so much traffic that they are able to sell prime space on their sites to link potential customers to a company's Web presence. For example, bookseller Barnes \& Noble recently announced that it will pay $\$ 40$ million to America Online (AOL; http://www. aol.com) to maintain its status as the online service's exclusive bookseller advertiser. In 1997, AOL received over $\$ 300$ million in revenue from these types of alliances [3]. ${ }^{1}$ In addition, Microsoft's new Windows 98 operating system allows the PC desktop interface to be transformed into a "Web site," complete with a set of preconfigured "channels." Because this powerful new Web gateway presence has the potential to alter the way users (especially new users) surf the Web, it has become a critical element of the U.S. Justice Department's ongoing investigation into Microsoft's alleged antitrust behavior.

4.2.3 Applications to Achieve a Global Presence. Clearly, one of the most powerful aspects of establishing an online storefront on the Web is that it immediately becomes accessible to the global community of Internet users. With proper

\footnotetext{
${ }^{1}$ See "Exclusive!" at http:/ / www2.computerworld.com/home/Emmerce.nsf/All/980112buzz.
} 
promotion and valuable content, even the smallest seller of goods and services can capture sales from distant locations. What has proven particularly useful in this area is niche retailers, who can establish themselves as unique to the online community.

An excellent example of this is HotHotHot! (http:/ / www.hothothot.com), the "Net's original hot sauce shop." By establishing itself as a niche player in the online marketplace, HotHotHot! has moved from being a small store with limited clientele to a well-known supplier of hot sauce worldwide. Similar examples include bookseller Amazon.com and online florist 1-800-FLOWERS (http://www. 1800flowers.com).

\subsection{Altering the Structure of Business Relationships}

4.3.1 Applications to Alter the Role of Intermediaries. In some industries, the Internet has created opportunities for new intermediaries to emerge that improve the efficiency of the buyer/seller relationship. When the user is faced with a multitude of online choices, some form of intermediary or filter is required to aid the user's search process. For example, Virtual Vineyards (http://www. virtualvin.com/) is a site devoted to wine and other specialty food items that for many shoppers are often hard to find. Virtual Vineyards acts as an intermediary between hundreds of small wineries around the country and the end customer, who often knows little about shopping for wine. By providing wine suggestions from Virtual Vineyard's expert wine tasters, menus, and other gift selections, this Web site adds efficiency value to the shopper, who otherwise might need to visit several locations to obtain similar results.

In other industries, we are observing a trend toward disintermediation, where manufacturers use their Web sites to sell directly to the end customer. This can occur in industries in which a manufacturer has a strong brand image and has significant market share in the physical retail space. The successes of Dell Computers (http://www.dell.com) and Gateway2000 (http://www.gw2k.com) shows the power of selling directly to end customers using their Web sites. In addition, some of the nation's largest automotive manufacturers are now beginning to experiment with direct sales to customer, thus bypassing the traditional auto dealership.

One of the most interesting opportunities for intermediation is in the personal financial management software industry. Here, Intuit, with its Quicken Suite, and Microsoft, with MS Money, are both vying to bypass banks and financial brokerages to become the aggregator of financial information for the individual investor. For example, Intuit has formed alliances with several major financial services companies, which allows Quicken 98 to use the Internet for online investment tracking. With this version of Quicken, the system automatically aggregates all of the user's financial portfolio onto a single interface, providing a powerful way to manage one's funds. Banks, brokers, and new entrants, such as Microsoft and Intuit, are battling to see who will be the new intermediary in the personal financial management industry.

4.3.2 Applications to Engage in Micromarketing to Look Small. Although the Web can be used to make small organizations look large, it can also be used by large 
organizations to look small by enabling micromarketing. By collecting information about the user, organizations can now target customers more effectively. These Web applications improve the user's information-gathering effectiveness, allowing organizations to essentially establish a one-on-one marketing relationship.

Firefly (http:/ / www.firefly.com) allows the user to build a personal profile of interests and individual characteristics that allow "Firefly-enabled" Web sites, such as bookseller Barnes \& Noble (http:/ / www.barnesandnoble.com) and music distributor myLAUNCH (http:/ / www.myLAUNCH.com), to make personalized recommendations of new books or CDs. In addition, Firefly uses the personal profile to link users with Firefly Venues that provide forums for people with common interests to communicate online with one another.

Another example of micromarketing is the use of cookie technology. When a Web site server is allowed to place a cookie on a user's hard drive, subsequent visits to the Web site inform the server what pages have been viewed by this machine in the past. In this way, the Web site is able to send tailor-made Web pages that have not been viewed previously. In addition, the system can make use of cookies to transmit advertising banners along with the Web page that are specifically targeted for that audience.

Finally, push technology, such as PointCast, allows news and information sites to post Web pages that are specifically tailored to meet the needs and interests of the individual user.

4.3.3 Applications to Create Dependency to Lock-In Users. These Web applications are strategic in nature in that they provide unique and valuable information that cannot be easily found elsewhere. In particular, if the provider of the information is able to encourage process changes at the user's facility to create greater dependency, the potential exists to lock the customer in to a long-term relationship [10].

In the midst of a sea of new online brokerage services, Schwab has established itself as a leader in online services and investment information. By constantly upgrading the value of the information provided, much of which is only available to existing Schwab customers, Schwab can lock in customers to a long-term relationship. By integrating this strategy with the move toward being a full-service brokerage, Schwab has learned that customers are willing to pay a premium for such services.

Another example is CNN Interactive, which has become the standard by which online news delivery is measured. CNN Interactive provides more than just current news that may be found on its television cable stations. The news service is in the process of developing an historical archive that is becoming increasingly valuable because of its comprehensive coverage and hyperlinks to related articles. Even though CNN Interactive is available free to all users, the news organization may eventually charge a fee for full access to its historical archive. As users of the service become accustomed to free access, they may alter their process of gathering historical information to take advantage of the Web site. Once the historical archive is so massive as to make it unlike any other historical database available on the Web and once users become locked-in to the service, $\mathrm{CNN}$ will be in a position to charge a fee for access and allow only certain external entities access to certain parts of its Web site. 


\subsection{Establishing New Types of Interaction}

4.4.1 Applications to Make Use of Extensive User Feedback. Not only can Web sites be used to alter the relationship between buyers and sellers, they can also be used to alter the nature of the interaction between the two parties. In particular, the two-way nature of the online interaction creates new opportunities to improve the user's efficiency by providing an easy, powerful, and fast way of giving feedback to the Web site administrator. Organizations that are able to make use of this two-way dialog can improve their core product offerings, the service available on the Web site, and customer service by gaining a better understanding of their customers.

One area where this may prove particularly useful is the retail banking industry. After a customer initially opens bank account(s), the opportunity for direct interaction with the customer is often eliminated because of the impact of automated teller technology. The opportunity for a bank to engage in face-to-face interaction with customers on at least a monthly basis is often limited to only one quarter of all account holders. Using Web feedback forms provides an excellent opportunity to "get to know" the customer in a new way.

Another example of making use of user feedback is McGraw-Hill's Bet@ Books site (http://www.pbg.mcgraw-hill.com/betabooks/). Based on the successful software paradigm, Bet@ Books allows users to view online complete text versions of selected emerging technology titles. The site allows consumers to "test drive" the books, then solicits feedback on the book before the final version is sent to print. The business model for this type of site is that there is the potential to sell more of those books that have had previous exposure to potential buyers. In addition, the authors of these books set themselves up to become well-known experts in their fields regardless of the sales volume of the actual book.

4.4.2 Applications Where the User Controls the Detail of Information Accessed. The user's information-gathering effectiveness can be improved by providing several levels of information detail and by allowing the user to drill down to the desired level. By putting users in control of the interaction, they are empowered to seek out the level of information required for their particular decision.

Many online catalogs contain varying levels of detail about product descriptions. Online banks provide customer account status, which allows the customer to download highly aggregated account information or to drill down to information about individual transactions. News organizations such as CNN Interactive allow readers to browse summaries of current articles, link to a specific article in its entirety, click on links to other Web sites mentioned in the article, and, finally, link to related articles in their historical database.

4.4.3 Applications Where Users Interact via Online Communities. One of the most powerful features of Web technology is the ability to create entirely new forms of virtual communities of interest. These Web applications are strategic in nature in that they create new levels of user loyalty by allowing the users to interact with one another via online forums $[7,8]$.

The Motley Fool (http:/ / fool.com) is a Web site that aims to "educate, amuse, and enrich" individual investors [5]. The idea is, that by trading information about 
personal investments with other investors, individuals can become better informed money managers and have fun at the same time. To do this, the Motley Fool provides an online bulletin board where users trade ideas and suggestions concerning use of a company's products and services, an online chat room where users can meet with various experts or the management of a particular company, and a bulletin board where users critique other people's investment strategies. The amusement aspect of this site promotes return visits, which results in significant advertising revenues. In addition, the site's designers have learned that quality content can be generated from free outside sources, which lowers maintenance costs and increases user loyalty.

Other similar examples include ESPN Sportszone (http://espn.com), which provides detailed sports news, discussion bulletin boards for all sorts of sports topics, generates interest via frequent online polls for "player of the week", and others; and the Intranet Journal (http:/ /www.intranetjournal.com), which provides expert advice and discussion bulletin boards for intranet and extranet builders.

\subsection{Opportunities to Create New Products and Services}

4.5.1 Applications to Automate Tasks Using Software Agents. One of the most powerful ways to use the Web to add value to the user is to use software agents to automate a series of time-consuming or otherwise unfeasible tasks. These Web-based applications improve the user's efficiency by using software agent technology to perform various tasks for the user.

Andersen Consulting's BargainFinder Agent (http://bf.cstar.ac.com/bf/) searches a number of Web sites to find the best price for a selected music compact disk. The agent then returns the name and link of the ten lowest priced online stores. By essentially reducing search costs to zero, this type of agent technology has the potential to radically alter online retail shopping. Competitors will need to find other ways to compete rather than by price through offering other value-added services [11].

IBM's Web Browser Intelligence is an intelligent software agent that aids the user in keeping track of previously visited Web sites, automatically notifies the user when selected sites are updated, indicates to the user the download speed of various servers, and monitors the user's Web usage patterns to generate "quantum links" to frequently visited pages. In addition, IBM's Personal Shopping Assistant can learn the shopping preferences of the user: When the user visits an online store, the Assistant rearranges merchandise so that the items the user likes are the first ones to be seen. In addition, it groups products together so that when one item is purchased, complementary items are made available for purchase (see http:/ / www.networking.ibm.com/iag/iaghome.html).

4.5.2 Applications to Provide Online Decision Support Tools. The content of an organization's Web site must be continuously updated to generate repeat visits to the site. One of the most promising types of content is the use of online decision support systems. These Web applications improve the user's information-gathering effectiveness by allowing the user to submit specific decision parameters and subsequently receive a suggested course of action [12]. 
The Schwab IRA Analyzer (http://www.schwab.com) aids individual investors in determining what type of individual retirement accounts are right for their particular situation. The online system receives input from the user, including tax filing status and income information, and generates advice regarding IRA options, links to various IRA products, and provides forecasts of accumulated account amounts based on additional user input.

The Molten Metal Blanketing Cost Analysis Program from Air Products (http://www.airproducts.com) allows trading partners to estimate the savings possible from using Air Products' inert gas blanketing technologies for induction furnaces. The user enters data concerning a particular furnace, energy consumption, residue disposal costs, and other pertinent parameters. The output is the projected savings using Air Products' technology.

Finally, Turner Mania is an extranet that is provided online by Turner Broadcasting that allows advertising executives to gather information needed to develop targeted advertising campaigns [10]. This online decision support system helps advertising managers put together entire advertising campaigns for Turner stations by indicating what type of ads would work well on which stations, at what times, and in what formats.

4.5.3 Applications to Bundle Information, Products, and Services. Organizations that are able to use several of the previously noted applications and are able to make use of the multimedia aspects of the Web to bundle information, products, and services have been able to create unique new product offerings that provide strategic advantage.

Motion Marketing Productions (http://www.motionmpi.com/) illustrates how streaming video coupled with other information can be used to promote real estate properties on a standard Web page, where the user can take a virtual tour of the home and view a panorama of the surrounding landscape. CNN Interactive uses streaming video to show news video clips and live video of important events such as presidential news conferences. This capability is revolutionizing the way that news is delivered. No longer is CNN limited to a few cable channels. Instead, $\mathrm{CNN}$ now can promote a limitless number of live video feeds, depending on user demand, and bundle them with their hypertext news stories: The user is put in total control of the news-gathering process. Using this video streaming technology, CNN Web casts its popular TalkBack Live show, complete with links to related news stories and an e-mail link that allows the user to send questions or comments to the show while it is in progress.

Other examples of bundling various multimedia aspects of the Web include a downloadable fashion show, complete with streaming video, links to product details, and an online ordering capability; and a university distance-learning course offered via the Internet, where streaming video is used to show the instructor in one frame, the synchronized overhead slide show in another frame, and links to related text in a third frame.

Another powerful example of the bundling strategy is Cendant's netMarket site (http://www.netmarket.com). It is an online shopping club where members can shop for retail goods, buy an automobile, gather information and book tickets for their next travel vacation, buy groceries, and even participate in an online auction. 
Any one of these sites would be valuable on its own, but by grouping them together, Cendant (formerly CUC International) has been able to put together a shopping club with over 70 million memberships!

Finally, iVillage (http: / / www.ivillage.com) promotes itself as the women's network, where the woman of the 1990s can find links to sites about parenting, career management, financial management, and health. This site promotes itself as an online community by making use of chat and online bulletin boards to promote discussion and also offers online shopping for various items of interest to women. This is just an example of how the bundling of information, products, and services creates a powerful online shopping experience for the user.

\section{APPLYING THE EC VALUE GRID}

The EC Value Grid provides a way of categorizing different features offered at online storefronts. To use the grid, managers should first determine which of the five dimensions of commerce to target for impact using the online storefront. Should the Web site be used to add value to the user by diminishing the time it takes to deliver information, products, or services? Are there distance barriers that need to be overcome to better serve customers? Is the objective to alter relationships in the industry, possibly by intermediation or disintermediation? Can the organization improve the nature of the interaction between industry parties? Or is the goal to use the technology to institute entirely new products and services that were not feasible before the introduction of the Web?

Second, managers must examine what type of value should be generated for the user. Is there a need to improve the efficiency of performing various tasks, improve the user's effectiveness in delivering timely information to decision makers, or use the technology to strengthen a long-term relationship with the user?

Once these questions have been answered, the Web manager can use the EC Value Grid to develop a Web-based application to bring about a particular type of business change by transferring an area of impact into new business value for the user. In addition, the grid can be used to benchmark one organization's online storefront with another storefront. The extent to which the Web site incorporates several cells in the grid becomes a measure of the strategic sophistication or EC coverage of the site. The goal for the Web manager should be to move from a simple online storefront, where theimpact is on time and distance to generate efficiency and effectiveness benefits, to vast electronic business sites that change the relationships in the industry, the mode of interaction with customers and trading partners, and produce creative new products and services to generate strategic value.

\section{REFERENCES}

[1] M. Hammer and G. E. Mangurian, "The changing value of communications technology," Sloan Management Review, pp. 65-71, Winter 1987.

[2] "The virtual mall gets real," Business Week, pp. 90-91, Jan. 26, 1998.

[3] "'net used to extend EDI's reach," Computerworld, p. 1, Feb. 23, 1998.

[4] "Virtual bookstores start to get real," Business Week, pp. 146-148, Oct. 27, 1997. 
[5] "Fools' logic," Internet World, pp. 68-73, Feb. 1998.

[6] J. A. Quelch and L. R. Klein, "The Internet and international marketing," Sloan Management Review, pp. 60-75, Spring 1996.

[7] A. Armstrong and J. Hagel, III, “The real value of on-line communities," Harvard Business Review, vol. 74, no. 3, pp. 134-141, 1996.

[8] J. Hagel, III and A. G. Armstrong, Net Gain-Expanding Markets Through Virtual Communities. Cambridge, MA: Harvard Business School Press, 1997.

[9] R. Kalakota and A. B. Whinston, Electronic Commerce: A Manager's Guide. Reading, MA: Addison-Wesley, 1997.

[10] F. J. Riggins and H. S. Rhee, "Toward a unified view of electronic commerce, Communications of the ACM, vol. 41, no. 10, Oct. 1998.

[11] J. Y. Bakos, "Reducing buyer search costs: Implications for electronic marketplaces," Management Science, vol. 43, no. 12, pp. 1676-1692, 1997.

[12] R. Kalakota, J. Stallaert, and A. B. Whinston, "Worldwide real-time decision support systems for electronic commerce applications," Journal of Organizational Computing and Electronic Commerce, vol. 6, no. 1, pp. 11-32, 1996. 